\title{
Research on the Application of the Flipped Classroom in the Cultivation of Normal Students' Information Technology
}

\author{
Ping $\mathrm{Li}^{\mathrm{a}}$ \\ Changchun Normal University, Changchun 130031, China. \\ accsy_lp@163.com
}

Keywords: flipped classroom, information technology, normal students, teaching practice

\begin{abstract}
The development of education informationization has had an important influence on the public course teaching of university information technology. It has brought severe challenge for teaching. This paper introduces the Flipped Class Model (FCM). Starting from the concept and successful application of the research, the FCM is applied to the teaching of university information technology course, and based on this model, an effective learning support system is constructed. Also a certain process control method is adopted to organize the teaching practice. Finally, through the study of the teaching practice, the application mode, scope and limitation of FCM mode are analyzed and discussed.
\end{abstract}

\section{Introduction}

With the development of information technology, information technology has become the basic requirements of the society for talents. During the process of teaching, how to develop teaching ability to improve the learning ability and practical application ability, has become a problem for teachers. At the same time, the information technology course is very important for the cultivation of students' innovation ability and cooperation ability. Therefore, the reform of the teaching mode and the structure of the information technology curriculum has become the focus of attention of many researchers. In many studies, the flipped classroom teaching mode (FCM) is one of the most teaching models in the last two years. The basic idea is that: when the traditional learning process is over, let ordinary students autonomous learn knowledge and concepts in overtime. The classroom for the interaction between teachers and students becomes the main place to answer doubts. Through the discussion of the report, the teaching effect can be better achieved.

\section{Basic Conditions of Normal School}

On one hand, FCM can promote students' autonomous learning and enhance students' knowledge of extra-curricular learning. Firstly, based on this reason, the students' autonomous learning ability and management ability are challenged. Secondly, it puts forwards some requirements for teachers' teaching. The teachers need to make a systematic summary of the contents of the flipped class learning, and carefully design the classroom teaching and management of learning resources. Teachers also need to provide the appropriate way to college students, so that normal students can develop their own learning habits. On the other hand, with the development of information technology, electronic learning methods and strategies become more complex. With the rapid development of the Internet learning platform, most of the learning resources are transmitted through information technology. Therefore, normal students should have the basic information technology capabilities, the application of a variety of types of network teaching platform, as well as the use of various types of multimedia resources. Some American institutions proves that the students have benefited from the use of inquiry based learning, project based learning and active learning. But from the point of view of promoting educational reform, FCM often uses video and other IT to encourage students to use digital devices and students can be more effective using digital devices. In the present teaching, the information technology education in normal education has 
already gone beyond the concept of normal education, and the use of the flipped classroom will promote the reform of normal education. It seems to be become the only way to go to the future.

\section{Application Research on FCM}

Since the beginning of 2007, the concept of flipped classroom was put forward, a lot of scholars have carried on the detailed research, and the results of the study were applied to practice, resulting in a wide range of influence.

\subsection{The Practice of VOLARE}

Italy scholar Marco Ronchetti put forwards a very innovative teaching strategy and mode based on the technology. He provided a very good business philosophy and it focused on exploring methods, rather than the traditional mode of network video teaching practice. He encouraged to take the strategy of FCM in the ordinary teaching, so that teaching can produce positive effective. In his research, the role of video was explored, and the students construct knowledge was analyzed. At the same time, the value of the study was analyzed based on the network video which could offer the FCM behavior and practical experience.

\subsection{The Influence of FCM to the Normal Students' Cooperation Ability, Innovation Ability and Task Orientation}

F. Strayer Jeremy, an expert on education and technology in the United States, has carried out the research on the practice of FCM in the aspects of collaborative ability, innovation ability and task orientation. Through the comparison between the experimental group and the control group, FCM has a significant effect on the cultivation of the ability of cooperation and innovation, and is an effective way to cultivate the students' cooperation ability, innovation ability and cohesion. However FCM has a negative effect on the training of learners' "task oriented".

Information technology courses in the University has a basic condition for the FCM. First of all, a majority of students have mastered a number of information technology capabilities, can skillfully use the Windows system, log on a variety of network platforms and operate a variety of multimedia resources. Secondly, the university teachers in the field of IT information technology may have some research, which can make good effects on the traditional learning resources, learning resources management and publishing tasks. Thirdly, the FCM is quite interesting. Most of the content is suitable for the task driven and teaching activities which can promote the organization of learning. Fourth, as the new century college students, some students already have a certain self-study and self-discipline abilities. In short, the quality of the students and the IT capability is feasible in the university classroom.

\section{FCM in Teaching Process}

\subsection{Teaching Process and Control}

(1) Organization of reading guidance and pre-test. At the end of the last lecture, the teacher should first set the learning requirements of the new curriculum. It mainly contains two aspects: firstly, prepare learning materials for learners. With teaching service platform to provide "learning content guide", the knowledge points and critical steps of new curriculum can be identified in the form of a question. Then design a practical comprehensive task, as a learning guide. Secondly, layout learning task. Ask students to read "Introduction", see the practical tasks, and then consider the issues raised in the introduction with practical solutions of the task. The goal of this course is to make the learners have a question, stimulate their desire to learn and form a strong internal learning motivation.

(2) Self-inquiry and discovery learning based organization extra-curricular learning activities. Teachers should provide the learning resource with the form of web, PowerPoint and micro video. And the use of knowledge map can provide navigation system for different cognitive style of the learners to choose. Learners should be aimed at guiding and practical tasks in question. In the extracurricular self-study, learners should solve the question in "reading guidance" and find an effective method to complete the practical task. 
(3) Classroom communication and knowledge internalization. In the new class, the teacher should assign some learners to report. This requires that the report of the technical and methods used to solve practical tasks to be explained in detail, and to other learners can have questions about the methods as well. Of course, the other students are more welcome to put forward new ideas, so as to realize the exchange and internalization of knowledge.

(4) To achieve knowledge of classroom practice, and prepare the next round of learning tasks. At the end of the class, the teachers need to lay out a certain amount of classroom work, curing the curriculum knowledge which is required to be completed and submitted. Also, the next round of "Reading Guidance" and "pre-test" should be prepared for the next round of learning.

\subsection{Influence of FCM for Normal Students}

Teaching practice has proved that the FCM encourages students to study independently in the classroom. Autonomous learning should take more time, which is conducive to explore the ability of innovation. Compared with the traditional classroom teaching, the flipped classroom exchange and share are very big advantages, rather than the traditional cramming teaching mode. This will be able to improve the communication and collaboration ability of the normal students. Therefore, the flipped classroom makes the students to collaborate and innovate, which is also conducive to the aggregation of class cohesion.

Along with the research, this makes the classroom may face the ideological collision. How to generate ideological collision in the classroom, and not just stay at a level of wandering is very important. In fact, it is easy to stall at a certain level of discussion and exchange and the in-depth comparison is hard to go on. The main reason is that the preparation may be insufficient. If students do not have the appropriate system to support the extracurricular learning, it is sometimes difficult to prepare in a limited time. FCM can reasonably guide the normal students to further study the information technology skills.

\section{Summary}

The development of information technology is posing a challenge to information technology course teaching. Thestudy, after defining flipped classroom model (FCM) and analyzing its application, attempts to apply FCM to information technologycourse teaching. Based on FCM, the teaching procedure is controlled and efficient learning support system is established in informationtechnology course teaching. In the last part, the application way, influence and limitation of FCM is analyzed and discussed.

FCM is an innovative teaching mode, which has overturned the inherent mode of traditional teaching. It is a major breakthrough in the development of modern information technology teaching reform. As an educator with the development of the times, we should not only stay in the stage of theoretical research, but should be more applied to teaching practice, so as to make due contribution to our country's modern education reform.

\section{Acknowledgment}

Fund Project: Changchun Normal University Humanities and Social Science Fund Project, Research on the Hybrid Teaching of the Vocational skills of Normal Students Based on Moodle Platform -- A Case Study of the Application of Information Technology. Project Number: Changchun Normal University Social Science [2013]012.

\section{References}

[1]. Gannod, Gerald C.; Burge, Janet E.; Helmick, Michael T. Using the Inverted Classroom to Teach Software Engineering. ICSE'08 Proceedings of the Thirtieth International Conference on Software Engineering, 2008: 777-786.

[2]. Lage, MJ; Platt, G. The Internet and the Inverted Classroom. Journal of Economic Education, 2000, (31):11-11. 
[3]. Marco Renchetti. The VOLARE Methodology: Using Technology to Help Changing the Traditional Lecture Model. TECH-EDUCATION, 2010:134-140.

[4]. Jeremy F. Strayer. How Learning in an Inverted Classroom Influences Cooperation, Innovation and Task Orientation. Learning Environ Res, 2012, (15):171-193.

[5]. Lage, MJ, Platt, GJ, Treglia, M. Inverting the Classroom: A Gateway to

Creating an Inclusive Learning Environment, Journal of Economic Education, 2000(31\&1):30-43. 